\title{
AÑORAR EL DESTIEMPO DEL 68. FUTUROS PASADOS PARA PRESENTES ABSORTOS EN ESPAÑA Y FRANCIA
}

\author{
Missing the 68' mistimes. Past Futures for Absent-Minded Presents \\ DAVID BEORLEGUI ZARRANZ \\ UNIVERSIDAD DEL PAÍS VASCO/EHU (ESPAÑA) \\ dbeorza@yahoo.es http://orcid.org/0000-0002-8982-5513
}

\author{
JESÚS IZQUIERDO MARTÍN \\ UNIVERSIDAD AUTÓNOMA DE MADRID (ESPAÑA) \\ jesus.izquierdo@uam.es http://orcid.org/0000-0002-5157-2637
}

RECIBIDO: 13 de MARZo de 2019 ACEPTAdo: 9 DE OCTUbRe De 2019

RESUMEN: Entre la distancia irónica y el gesto doliente, la memoria del definido como "año más histórico de la edad contemporánea" amenaza con verse petrificada tras el retorno a un pasado contemplado como extraño y ajeno a las coordenadas del presente. A diferencia de aquella generación que pensó su futuro como la expectativa de un progreso que dejaba atrás el pretérito del consumo y la burocracia, la nuestra, desafecta con el futuro emancipador de la modernidad y con el presente distópico en el que nos vemos progresivamente sumidos, dirige sus ojos nostálgicos hacia un ayer donde lo posible y deseable han sido devastados por la práctica de lo conocido infranqueable, inclinándonos a miradas retrotópicas que hacen del pasado un lugar que nunca debimos abandonar. Este artículo propone una lectura interpretativa de la memoria del sesenta y ocho que parte de los presupuestos teóricos de la historia oral y de los estudios culturales de la memoria. Atendiendo al modo mediante el que los sujetos representan el tiempo histórico para dar sentido a sus vidas, el texto se propone repensar el sesenta y ocho desde la actualidad de sus futuros pasados, invitando a recuperar una parte de su carga utópica para los futuros que aguardan por venir.

PALABRAS CLAVE: Mayo del 68, memoria, pensamiento utópico, temporalidad.

ABSTRACT: Between ironic distance and weeping gesture, the memory of the so-called "most historical year of contemporary history" is threatened of being petrified after returning to a past seen as strange and alien to the coordinated of the present. Unlike that generation that thought its future as the expectation of a progress, that left behind consumption and bureaucracy, ours, disaffected with the emancipatory future of modernity and the distopic present in which we are progressively sunk, directs its gaze towards a past. In this past the possible and desirable have been devastated by the practice of the known as impassable, leaning toward retrotopic views that make the past a place we should have never abandoned. This paper proposes an interpretative reading of the memories of 1968 departing from the theoretical assumptions of oral history and cultural studies of memory. Considering the way by which subjects represent historical time to give meaning to their lives, the text rethinks the 68 from the actuality of their future pasts, inviting to recover part of its utopian surplus for the futures awaiting to come.

KEYWORDs:May 68, Memory, utopian thought, temporality.

Beorlegui Zarrranz, David e Izquierdo Martín, Jesús.

"Añorar el destiempo del 68. Futuros pasados para presentes absortos en España y Francia"

Kamchatka. Revista de análisis cultural 14 (Diciembre 2019): 587-601.

DOI: 10.7203/KAM. 14.14279 ISSN: 2340-1869 


\section{A VUELTAS CON EL PASADO1}

$$
\begin{array}{r}
\text { "la nostalgia, en cuanto a emoción histórica, es la añoranza de } \\
\text { ese "espacio de experiencia" menguante que ya no encaja en el } \\
\text { nuevo horizonte de expectativas". } \\
\text { Boym, 2001, } 34^{2}
\end{array}
$$

Regresa el 68 pero no sabemos cómo retorna. Viene de la mano de una conmemoración, pero la intención es que pase como otra mercancía retro, como una pieza más de este museomausoleo donde la modernidad gira su vista, fijándola en el pasado. Resulta cuando menos llamativo que, como señalara Jacques Derrida, se trate de un acontecimiento que no sabemos "denominar de otra forma más que con una fecha" (citado en Leguineche, 1999: 508). Identificado por algunos autores como la última gran oleada revolucionaria europea, el 68 vendría a constituir el epicentro de lo que Marwick denominó "los largos años sesenta", un clima de radicalidad política y cultural que imprimiría con su sello distintivo a los movimientos de la época y permitiría afirmar, como hacen Balestrini y Moroni, que nada volvió a ser como antes después de aquello (Marwick, 1998: 43; Balestrini y Moroni, 2006). Atendiendo a las transformaciones introducidas por el 68, Wallerstein consideró que este acontecimiento representó una verdadera revolución en el "sistema mundo", un movimiento sísmico que se hizo sentir en lugares tan dispares como Europa Occidental, Estados Unidos, América del Sur o Japón, modificando para siempre tanto los lenguajes como los análisis de la izquierda (Wallerstein, 1989: 229-250). Para Antonio Negri, Mayo del 68 habría supuesto "el nacimiento del siglo XXI". La importancia e intensidad de ese momento y los ríos de tinta que se han escrito en torno a él explican que algunos comentaristas lo hayan denominado "el año más histórico" del pasado siglo XX (Mc Laughin, 2014).

La dimensión internacional del 68 no ha pasado inadvertida a los actuales especialistas, siendo descrito fundamentalmente como un desafío colectivo contra ciertas instituciones, normas sociales y formas de pensamiento (Gildea, Mark y Warring, 2013: 1). A diferencia de aquella generación que pensó su futuro como expectativa de un progreso que dejaba atrás el pretérito del consumo y la burocracia, la nuestra, desafecta con el futuro utópico, descreída de los pronósticos distópicos o acostumbrada a la banalidad de lo antiutópico, dirige sus ojos nostálgicos hacia un deseado ayer que ha sido devastado por la práctica de lo conocido, por una estricta delimitación entre lo posible y lo infranqueable. Lejos de permanecer ajena a ese proceso, la historiografía viene interviniendo en el proceso de construcción de la memoria sesentayochista, insistiendo una y otra vez en agotar el potencial semántico de ese acontecimiento y en circunscribirlo a cronologías cerradas (apenas un mes de un año concreto), a espacios concretos (la capital francesa) y a grupos claramente delimitados (estudiantes y trabajadores).

La producción de distancia histórica y la despolitización de la memoria obligan a interpretar el acontecimiento como hecho histórico muerto, solo digno de observación cientificista. Ahora bien, ¿no podríamos dejar de lado este afán de anticuario por el 68 y comenzar a repensar la

\footnotetext{
1 Por parte de David Beorlegui en artículo se ha redactado gracias a la Convocatoria de contratación para la Especialización de Personal Investigador Doctor en la UPV/EHU ESP/DOC18/17.

2 Svetlana Boym, El futuro de la nostalgia, Madrid, Antonio Machado Libros, 2015 [2001], p. 34.
} 
nostalgia por ese acontecimiento como un elemento que desate nuevas hebras en la construcción de nuestros pequeños futuros? Este texto aboga por un diálogo productivo entre la Historia y la Memoria al entender, junto a Enzo Traverso, que su separación radical es una operación en extremo "discutible y peligrosa" (Traverso, 2007: 21). Ciertamente, el sentimiento nostálgico ha resurgido con fuerza en estos últimos tiempos, con su semántica más restauradora, con su intransigencia más aversiva contra lo novedoso y con su obsesión por la recuperación de un deseado y posible viejo orden; en fin, con su ideal en torno a pasados gloriosos y a las antiguas injurias contra enemigos supuestos. El imaginario colectivo de la vieja nación en los países de ingreso reciente en la Unión Europea pertenece a esa lógica de la nostalgia restauradora, dominada por la sombra de imperios deseosos de reestablecer viejas fronteras y de imaginar antiguas comunidades étnicamente limpias. No obstante, existe también, según indagó la teórica soviética Svetlana Boym que aparece al inicio de este texto, otra nostalgia menos compulsiva y más reflexiva, más personal, que se enmarca en la neblina lejana del pasado y en la pérdida irrecuperable, donde la temporalidad es una suerte de vivencia de un exilio interminable para el cual los eventos pretéritos son rememorados como momentos preciosos y limitados en los que sentimos que la vida podía ser sacrificada en favor de un futuro repleto de posibilidades. Así pues, y en sintonía con el planteamiento de Boym, podríamos considerar la nostalgia como parte constitutiva de una "incurable condición moderna", un síntoma secundario de la teleología del progreso, pero una nostalgia que considera los acontecimientos pretéritos, no como lugares a los que regresar, sino como episodios con los que pensar el presente que vivimos y el futuro que deseamos (Boym, 2015). Este es el centro de la propuesta que hacemos en el presente texto: aproximarnos, desde el pensamiento crítico y la esperanza creativa, a la evocación de aquel manido Mayo del 68 como un acontecimiento que sigue sucediendo en nuestra imaginación colectiva, no como objeto enterrado, sino como artefacto activo en la desestabilización de nuestros lugares comunes.

\section{EL MAYO DE LAS EXPECTATIVAS}

Lo relevante de ese momento fue "su determinación a actuar, su júbilo en la acción y su confianza en la capacidad para cambiar las cosas con su propio esfuerzo". Arendt, 2016: 204 [1970] ${ }^{3}$

Mayo del 68, en su experiencia, fue un acontecimiento que se situó en el mismo vórtice del tiempo de la modernidad: se alimentó de la misma teleología del progreso por cuanto todo su accionar se focalizó en la mejora futura y en una relevante irreflexión sobre el pasado en cuanto este era, sobre todo, experiencia de superación. Algunos de los emblemas acuñados en la universidad de la Sorbona durante aquel año expresaban este sentir temporal: "Un pensamiento que se estanca es un pensamiento que se pierde". El tiempo discurría favorablemente al cambio y a la ruptura con la tradición; las experiencias pasadas dejaron de tener sentido frente a un horizonte de expectativas en el que se aspiraba a alcanzar un universal que superase lo local

\footnotetext{
${ }^{3}$ Hannah "ARENDT, "Pensamientos sobre política y revolución. Un comentario. (Entrevista concedida a Adelbert Reif en 1970)”, en La última entrevista, Barcelona, Página Indómita, 2016.
} 
(sobre la conformación de la temporalidad moderna, véase Koselleck, 1993). El 68 engendró así su propia temporalidad, "compuesta por repentinas aceleraciones y efectos inmediatos" (Ross, 2008: 201). La intensificación de esa experiencia del tiempo aparece descrita por Tomás Ibáñez, participante en las protestas: era como estar "atrapados en un ritmo desenfrenado, vertiginoso, mezcla de exaltación y de agotamiento, impresión muy fuerte de estar haciendo historia, de ser protagonista, de estar teniendo efectos sobre la realidad, de estar confrontados a desarrollos imprevistos que superar a sus protagonistas y, por un tiempo, con la impresión de ir cada día a más” (Ibáñez, 2018: 62). Como planteara Passerini, Mayo del 68 comportó una intensificación del impulso utópico definida por su "sentido de inmediatez, de vida vivida con emergencia", una percepción más o menos extendida de que "había nacido un tiempo nuevo", lo que implicó experimentar "un cambio temporal en su sentido más pleno" del que habría de emerger una nueva subjetividad política, descrita como la sensación de "nacer dos veces" a partir del "sentido ardiente de vivir el fin de los tiempos" (Passerini, 2006: 75).

Los verbos relacionados con el accionar, frente a los vinculados con la reflexión, adquirieron todo su sentido en el acontecimiento 1968, un momento definido significativamente como "movimiento" o como serie de "movimientos". Aquello, como sostiene el fotógrafo Bruno Barbey, fue un sueño de utopías por "el amor libre, el reino de los parias de la tierra y tumbar la Francia del general De Gaulle" (Barbey, 2018). Para Claire Auzias, integrante del Comité de Acción de Estudiantes de Secundaria, se trataba de la reunión, casi comunión, de "millares de grupúsculos aislados", que "se brindaban gozosamente a sí mismos una rebanada de Historia" (Auzias, 2018: 116). Kristin Ross también ha considerado el 68 como acción indisociable de la actividad frenética de distintos grupos de izquierda por traer al suelo europeo las luchas que tenían lugar en los antiguos territorios colonizados, así como por favorecer el ansiado, casi soñado encuentro, entre la clase obrera y los grupos de estudiantes más movilizados (Ross, 2008). Estos esfuerzos por accionar el movimiento, también en su versión más virulenta -la de la violencia armada-, han sido progresivamente silenciados por cierta memoria construida en torno al acontecimiento 68; una memoria tendente a considerar, en su versión más conservadora, que "nada ocurrió" entonces. Es la lógica que impera en esa forma de estar en el mundo articulada en torno al antiutopismo, tan de moda en nuestro nuevo tiempo de "silencios y olvidos" (Passerini, 2006: 26).

Mayo de 1968 en España siempre estuvo atravesado por la especificidad de la lucha contra la dictadura. La agitación estudiantil que se venía conformando en el interior de las universidades consistió en una de las principales preocupaciones del régimen franquista. Cabe destacar también la proliferación de grupos que se posicionaban a la izquierda del PCE y que impulsaron un nuevo sindicalismo obrero con un carácter social y político cada vez más acusado. (Wilhelmi, 2016; Beorlegui, 2017). Las manifestaciones de descontento que se fueron abriendo paso a partir de esa fecha los distintos escenarios de oposición al régimen venían a conectar a España con una voluntad emancipadora e inequívocamente revolucionaria que le daba al 68 el carácter de acontecimiento global (Pastor, 2009). Aunque la historiografía ha insistido en que "nada pasó" en el 68 español, lo cierto es que la intranquilidad de las autoridades ante lo que estaba ocurriendo en el país vecino fue más que evidente. En una nota de una Comisión de Estudios vinculada al gobierno español y fechada el 22 de mayo, la situación aparecía descrita como una "[...] grave crisis política que intranquiliza a la mayor parte de la población, con las huelgas que paralizan la 
vida nacional, las ocupaciones de las Universidades y Fábricas, extremos éstos que no se habían visto desde las jornadas revolucionarias de 1936 [...]” (Extraído de Fleites, 2009: 165).

En un contexto de efervescencia movilizadora, las referencias a la guerra no eran casuales; más bien trataban de recordar la legitimidad de origen del régimen e implicaban el retorno a mecanismos de represión excepcional que lo habían caracterizado en el pasado. Atendiendo a este hecho y a los comentarios de los mandos policiales franquistas durante 1968, el embajador francés en Madrid aseguraba a sus superiores que "si la situación hubiera sido igual en España, los muertos se habrían contado por miles" (Extraído de Casanellas, 2014: 105-106). La expresión del 68 en España no tendría, desde luego, la espectacularidad que alcanzaron las protestas en el país galo, pero si compartía con estas su significado más profundo: el accionar del movimiento y hacer sentir a sus participantes parte de algo grande que desbordaba las fronteras de la dictadura. Aunque el régimen se caracterizaba por su actitud paranoide y represiva ante cualquier acontecimiento interpretado como subversivo, los franquistas estaban particularmente convencidos de que amplios sectores juveniles se disponían a pasar a la acción directa. No en vano, ese mismo año el movimiento estudiantil, aunque debilitado, había conseguido retirar el decreto de creación de la Policía de Orden Universitario.

Uno de los aspectos más destacados de las luchas que emergieron a finales de los años sesenta tiene que ver con la centralidad que ocupó el componente obrerista, situación que hizo que un importante número de estudiantes acudiera a las fábricas en busca de las masas llamadas a protagonizar un salto emancipador hacia el futuro. Esa asunción supuestamente inapelable motivó que Mariví Marañón optara por encaminarse al mundo obrero: “yo no estudiaba más... que pa qué... ahora que están las fábricas, a hacer la revolución. Objetivo: hacer la revolución. ¿Dónde se hace la revolución? Pues en las fábricas"4. Como recuerda Luis Alejos: "hasta los hijos de familias bien situadas iban a la fábrica", movidos por el axioma de que "había que hacer la revolución, y la tenían que hacer los obreros". En su caso, los inicios en la militancia coincidieron con su ingreso en el ESBA, la rama vasca del Frente de Liberación Popular, de tendencia castrista. El entrevistado todavía recuerda como en pleno tardofranquismo "llegó un momento en el que alguien decidió que había que hacer algo más que manifestaciones... y huelgas (...) empezamos a hacer prácticas... primero de cócteles y tal... pero la idea era seguir avanzando y formar un grupo armado"s.

Dada la amenaza que representaba el 68 para las autoridades del régimen, no resulta extraño que la fecha coincida con episodios represivos que son interpretados, en muchos casos, como pistoletazos de salida de prolongadas trayectorias militantes. Mari Carmen Moreno, militante entonces en ETA berri, de la cual surgiría luego el Movimiento Comunista de España

\footnotetext{
${ }^{4}$ Entrevista realizada a Mariví Marañón el 15 de abril de 2009. Autora de la entrevista: Mentxu Irusta. Nacida en Medina de Pomar (Burgos) en 1943, Mariví Marañón formó parte de la JOC durante los años sesenta y se sumó a finales de la década a Komunistak-ETA berri, posteriormente MC-EMK. Su actividad se centró durante los años setenta en el sector fabril y el impulso de las Comisiones Obreras en Bizkaia. Entrevista recogida en el Archivo AHOA, colección "Luchas obreras en Bizkaia (1970-92).

5 Entrevista realizada a Luis Alejos el 31 de marzo de 2009. Autora de la entrevista: Mentxu Irusta. Luis Alejos nació en Palencia en 1943, pasando a vivir a Bizkaia con tres años. Sus inicios en la militancia se dieron en las filas de ESBA, pasando posteriormente como independiente a Comisiones Obreras y uniéndose posteriormente al EMK. Entrevista recogida en el Archivo AHOA, colección "Luchas obreras en Bizkaia (1970-92).
} 
(MCE), considera la fecha como año clave de su prolongada trayectoria como comunista y no oculta su sorpresa cuando recuerda el momento en que fue detenida: "El libro rojo estaba en mi casa, cuando la poli vino por primera vez a mi casa. Fue... en el 68, fue -rememora Moreno- Yo tenía el libro rojo en casa. ¡Tenía el libro rojo en casa, en el 68!" (risas)" ". Las palabras y la actitud adoptada por la entrevistada resultan muy esclarecedoras del significado fundacional que adquiere esa fecha con respecto a su identidad política y del modo en que se convierte en un hito en la conformación de su memoria. De modo muy similar, Juan Ramón Garai se refiere a su detención al cruzar la frontera gala en 1969: "cuando llegamos al seiscientos... teníamos las cuatro ruedas pinchadas y nos aparecieron treinta guardias civiles y nos detuvieron -recordaba entre risas con resignación- ¡y yo tenía en el gallinero unas hojas de la guerra del Vietnam! (...) propaganda ilegal. Nos tuvieron en sumarísimo durante bastantes meses. Sumarísimo significaba que por propaganda ilegal te podían condenar a pena de muerte"7.

Francia, Argelia, Cuba, China, Vietnam... y España: los actores de aquel 1968 internacional articularon pues su accionar a partir de expectativas utópicas que permitían pensar lo deseable como factible, desafiando las lógicas de lo posible y el miedo a ser detenidos. Su temporalidad fue por eso la de la utopía, como lo fue también la articulación de una lógica de resistencia antifranquista que preveía el cambio radical frente a un régimen dictatorial cargado de matices retrotópicos y antiutopicos (Artimé, 2016). Las medidas represivas excepcionales que se pusieron en marcha a partir del 68 vinieron justificadas por la necesidad de imponer el orden social frente al desorden. Los periódicos españoles de la época invistieron de este sesgo a lo acontecido en Francia, en una línea muy clara con la temporalidad del régimen franquista ${ }^{8}$. Esta lectura inquietante del 68 experimentó, sin embargo, importantes transformaciones como consecuencia de un incesante trabajo de despolitización de la memoria, que en el caso de nuestro país coincidió con los primeros pasos de la transición política.

\footnotetext{
${ }^{6}$ Entrevista realizada a Mari Carmen Moreno el 15 de abril de 2009. Autora de la entrevista: Mentxu Irusta. Nacida en Bilbao en 1942, Mari Carmen Moreno comenzó como activistas en movimientos católicos de base. Durante 1966 estuvo involucrada en la organización de la huelga de Bandas, la más importante del período. Desde finales de los años sesenta estuvo en formaciones maoístas y desempeñó una labor sindical importante en fábricas como Artiach y Firestone. Entrevista recogida en el Archivo AHOA, colección "Luchas obreras en Bizkaia (1970-92).

${ }^{7}$ Entrevista realizada a Juan Ramón Garai el 22 de julio de 2009. Autora de la entrevista: Mentxu Irusta. Nació en 1949 en Arrasate (Mondragón). En 1967 ingresó en ETA, siendo detenido y encarcelado en 1969. Durante los años setenta se posicionó con la VI Asamblea, posteriormente liga Comunista Revolucionaria. Centró su actividad en el mundo fabril del Alto Deba. Entrevista recogida en el Archivo AHOA, colección "Luchas obreras en Bizkaia (1970-92).

8 ABC declaraba "Ya hay un muerto en Francia. Era lo que los revoltosos pretendían a través de una escalada de violencia". El Alcázar lo calificaba de "guerrilla urbana", mientras Arriba amenazaba con que "Los estudiantes enrabiados han desbordado ya la universidad". La Vanguardia iba más lejos advirtiendo de los "gravísimos disturbios provocados por los estudiantes" (citas extraídas de "1968. Así lo contó la prensa”, El Mundo, 2018).
} 
Jesús Izquierdo Martín, David Beolegui Zarranz. Añorar el destiempo del 68...

\section{TIEMPO DE RETROTOPĹAS Y ANTIUTOPÍAS. UN 68 MUERTO Y ENTERRADO}

"Cuándo no hay novedad real, ¿qué queda de ellos [movimientos juveniles]? ¿Qué ha sido de los jóvenes de Berkeley de 1964, de los de mayo de 1968 en París? ¿Hay algo más pasado, más anticuado y sin esperanza de resurrección?”

Marías, 19779

Aunque el 68 estuvo orientado hacia el futuro de modo decidido, la posterioridad del movimiento está, no obstante, marcada por una distinta temporalidad. Como ha sostenido Zygmunt Bauman en su obra póstuma, probablemente hayan sido la ofensiva neoliberal de la segunda mitad de la década de 1970 y la quiebra de su modelo alternativo de sociedad representado por la Caída del Muro de Berlín en 1989, los grandes episodios que explican el desconcierto de las manifestaciones más utópicas de la sociedad occidental (Bauman, 2017). Y es que el último cuarto del siglo XXI se ha caracterizado por el relativo desmantelamiento de las narrativas históricas del optimismo, de las figuraciones con ánimo realista donde el futuro era realizable exclusivamente por unas instituciones que, pese a sus notables deficiencias, superaban con creces el horizonte heredado tras la Segunda Guerra Mundial y la Guerra Civil española. Este desmantelamiento del futuro afecta incluso a ese conjunto de distopías que vaticinaban, a través de numerosas imágenes y textos, la llegada de un futuro indeseado. Su declive es simultáneo al decaimiento de sus condiciones de realización pues Occidente lleva un tiempo conviviendo, sin reflexionar en exceso, con una suerte de presente continuo, ensimismado en un individualismo para el cual lo social es un coste futuro que desmerece la inversión pasada de quienes forman de su imaginario colectivo. En expresión de Bauman: "ya no se divisa en el futuro ninguna sociedad que ligue de una vez por todas la perfección individual a la social, y tampoco sirve de nada esperar que la salvación vaya a venir de la sociedad" (Bauman, 2017: 20).

Quienes estuvieron y están contra Mayo del 68 lo interpretaron y lo interpretan desde una narrativa antiutópica que pretende defender el orden vigente ante la amenaza de las manifestaciones que se sucedieron principalmente en Francia. Fue y es una forma de pensamiento conservador que se iría intensificando a lo largo del último tercio del siglo XX en una suerte de obsesión despolitizadora que ignora el componente radical de los movimientos que emergieron entonces. Un gran número de analistas franceses de nuestro tiempo, algunos de ellos actores o testigos de los acontecimientos, consideran, como Philippe Tesson, que "dejó una especie de vergüenza en la memoria colectiva" (extraído de Hermoso, 2018). En una entrevista a la Agencia Magnun, el ya mencionado fotógrafo Barbey, sostiene que aquello "no fue otra cosa que una revuelta de estudiantes y de hijos de la burguesía en uno de los países más ricos del mundo". Otros piensan que, tras la llegada de Mitterand al poder en 1981, el modelo se agotó después de la integración de sus líderes al sistema y su propia institucionalización; y es que, según Le Goff, Mayo del 68 fue un movimiento sin mesura que no generó una verdadera alternativa política y solo contribuyó a destruir sin construir nada a cambio (Le Goff, 1998). De manera que, frente a la celebración laudatoria del cuadragésimo aniversario, la actual conmemoración se ha enfriado en un país donde el paro masivo y el terrorismo ocupan el tiempo de una sociedad en la

9 Julián Marías, "El ejercicio de la libertad”, El País, 14-08-1977. 
que importantes grupos de jóvenes no quieren saber de aquel momento y votan al Frente Nacional con el deseo de retornar a valores autoritarios y a la vieja nación ${ }^{10}$. Hay, por consiguiente, un cierto sentimiento de nostalgia restauradora que busca en el pasado previo al 68 el paraíso perdido y que pretende hacerlo desaparecer. Ya en la campaña electoral del Nicolas Sarkozy de 2007, éste afirmó con contundencia: "En esta elección se trata de saber si la herencia de Mayo del 68 debe perpetuarse o si debe liquidarse de una vez por todas. Quiero pasar página de Mayo del 68" (Extraído de Cebeiro, 2018). Con todo, la reciente controversia que hubo en Francia tras anunciar el presidente Emmanuel Macron su intención de conmemorar oficialmente las protestas del 68 constituye la última muestra de la vigencia del tema en la sociedad gala, por lo que parece que su legado dista mucho de haber sido eliminado de la arena pública y política.

Para el caso español, la interpretación antiutópica del 68 hunde sus raíces en los primeros vaivenes del proceso de transformación política que, conocido como transición, pasó a dar nombre a una etapa fundacional de nuestro presente histórico. $\mathrm{Y}$ es que como señala Jordi Ibáñez, la transición fue ante todo la percepción más o menos extendida de que "el tiempo adquiría otro sentido" (Ibáñez, 2009, 193). El propio término transición resulta del todo significativo, al proponer una especie de movimiento necesario hacia el futuro que no tiene un punto de arranque concreto, al modo del acontecimiento. Identificada por Julián Marías como "el triunfo de la razón histórica", la transición suponía la entrada en un tiempo radicalmente nuevo que ponía fin al pasado tenebroso de la guerra y la dictadura, pero también a los sueños alumbrados al albor de las luchas del 68. De ese modo, "España no había sido liberada después de 1975", sino que había "empezado a ejercer su libertad y se ha puesto, de un brinco, en el presente". La fórmula elegida por Marías para describir la entrada en una nueva temporalidad como consecuencia de la apertura del pasillo transicional, la del presente, requería huir tanto del pasado del 36 y el franquismo como, sobre todo -y sorpresivamente-, de "los llamados movimientos juveniles"11.

Desde que el 68 fuera muerto y enterrado, mucho se ha escrito al respecto. Según Lola Iturbe, veterana militante libertaria en el exilio, en noviembre de 1968 el número de libros publicados al respecto superaba ampliamente el medio centenar (Iturbe, 2018: 150). Lo que conviene tener en cuenta es que, ya sea para atacarlo, ya para defender sus planteamientos, no son pocos los que piensan que Mayo del 68 ha dejado de tener efectos políticos para convertirse en objeto histórico. Y este fenómeno es especialmente impactante en el mundo editorial español en términos relativos si lo comparamos con lo ocurrido en Francia. Mientras en este último país, la conmemoración parece haberse enfriado, en España ha habido una suerte de eclosión editorial y conmemorativa. Libros como los de Tomás Ibáñez, Gabriel Albiac, Patricia Badenes, Joaquín Estefanía, Antonio Elorza, Ramón González Férriz o Luis Zaragoza se han sumado a la multiplicación de retrospectivas al igual que a artículos o especiales de periódicos de tirada nacional o local. El acontecimiento se ha convertido, como ya hemos sostenido, en el foco del ojo analítico del científico social o del inquieto anticuario. Para estar muerto y resucitado desde

\footnotetext{
10 La obtención por parte del Frente Nacional del 23\% de los votos en las elecciones de mayo de 2019 vino a corroborar la tendencia alcista de su partido pronosticada por las encuestas. La irrupción de Vox en el caso español con algo más del 10\% de los votos y 24 diputados también fue interpretado como la inserción de España en contexto europeo y mundial de ascenso de la extrema derecha.

11 A esta cuestión se dedican las preguntas que abren este epígrafe.
} 
hace varias décadas, el 68 sigue cotizado al alza en circuitos mediáticos y académicos, arrojando suculentos réditos a la sombra de las conmemoraciones.

Indudablemente, España no escapa a la tensión moderna entre pasión por el progreso y angustia desatada por la desaparición del pasado. La fragilidad del presente entre el futuro deseado y el pasado superado es uno de los síntomas de la modernidad que vivimos con la suficiente nostalgia como para que el pretérito sea también aquí motivo de conmemoración. Ahora bien, más allá de las pretensiones monopolistas de los científicos sociales y los historiadores, aquí además se suma un motivo de celebración no menos importante. Como nos recuerda una vez más Barbey, compañero de otros dos grandes fotógrafos del movimiento, Gilles Caron y Jean-Pierre Rey, en una entrevista recogida por El País: "Siempre me ha llamado la atención la forma en que los españoles se sienten atraídos por los acontecimientos del mayo del 68: la razón, pienso, es que sigue habiendo toda una generación frustrada que, bajo la dictadura de Franco, nunca pudo pensar en vivir unos hechos así. Y siguen queriendo entender qué es lo que de verdad pasó en París en aquellos días" (Barbey, 2018).

Lo cierto es que Mayo del 68 se convirtió pronto en España en un acontecimiento vivido con especial anhelo por quienes lo experimentaron fuera o dentro de las fronteras y se preguntan sobre los límites locales para que algo así tuviera lugar aquí. Algunos de los núcleos urbanos situados más próximos a la frontera gala fueron quizás los que acusaron con mayor intensidad los influjos de la subversión sesentayochista. Obligada a marchar al exilio en 1970 tras ser detenida en una protesta universitaria, Maialen Aizkorbe pensó en Francia. Su decisión de marchar al país galo, como ella misma recuerda, vino motivada en gran medida por su creencia en que allí eran "maestros en revoluciones ¿eh? desde la del ochenta y nueve, la del setenta y uno, la Comuna... de París, que esa no fue triunfante, pero... oye son muy revolucionarios, la del sesenta y ocho que fue otra cosa, pero... yo que sé... ¡Mayo del sesenta y ocho!”12. Evocando lo sucedido en Francia y también en los campus estadounidenses, Marco Odena organizó una retrospectiva sobre mayo del 68 en unos Encuentros de Arte que se celebraron en 1972 en la capital navarra. Odena recuerda que la conmoción y la polémica causadas obligaron a retirar varias obras, asegurando a lo largo de su proceso de rememoración que el ambiente que se respiraba era como "muy... que se podía traer todo aquello, traer aquí... estábamos viviendo todo eso con ansiedad, y jojalá hubiera podido ocurrir algo parecido...!'13. Otro activista de la época, José Ramón Castaños, recordaba su llegada a la capital francesa en 1972, huyendo de la represión en Bizkaia. Allí

\footnotetext{
12 Entrevista realizada a Maialen Aizkorbe (seudónimo) el 11 de mayo de 2012. Autor de la entrevista: David Beorlegui. Nació en 1949 en un pueblo de la Navarra media. A finales de los años sesenta formó parte del movimiento estudiantil y se vio obligada a exiliarse a Francia. Allí tomó contacto con miembros del PC (ml), formación en la que militó durante la práctica totalidad de la década de los setenta. Entrevista recogida en el Archivo AHOA, colección "Nuevos movimientos sociales y activismo político en el País Vasco en las décadas de 1970 y 1980).

13 Entrevista a realizada a Marco Odena (seudónimo) el 20 de abril de 2011. Autor de la entrevista: David Beorlegui. Nació en 1942 en Pamplona, formando parte de la agitación antifranquista en la capital navarra durante los años sesenta y setenta, sin llegar a militar en ninguna formación concreta. Desarrolló un papel importante como dinamizador de grupos de artistas caracterizados por su compromiso político y social. Colaboró en la organización de los Encuentros de arte de Pamplona en 1972, un hito para los reducidos sectores de contracultura en la región. Entrevista recogida en el Archivo AHOA, colección "Nuevos movimientos sociales y activismo político en el País Vasco en las décadas de 1970 y 1980).
} 
encontró "un ambiente que era muy proclive precisamente al romanticismo revolucionario, que es justamente el que llevábamos nosotros". A partir de entonces, aseguraba el entrevistado, tuvo lugar la introducción "a borbotones" de una "interpretación del marxismo" vinculada a "los pensamientos del 68, [que] no cabe ninguna duda de que sí, fue muy positiva para las organizaciones de aquí, de la clandestinidad, del interior... un campo de pensamiento que aquí no habíamos trabajado"14.

Para el caso de Cataluña, el 68 prendió con fuerza en ambientes estudiantiles y universitarios, adquiriendo una presencia progresiva en las calles que tuvo su apogeo en las ramblas a mediados de los setenta, coincidiendo con un pico huelguístico sin precedentes en los barrios obreros del extrarradio. Pepe Ribas, uno de los fundadores de la revista Ajoblanco, eligió precisamente aludir a la recepción del 68 en las primeras líneas de su voluminosa autobiografía "Los 70 a destajo", señalando que: "Robé el librito < La imaginación al poder: París, Mayo 1968, la revolución estudiantil $>$, a las tres de la madrugada, en una librería de excepción, la del drugstore del Paseo de Gracia. Fue el 14 de febrero de 1972 tras una jornada de lucha en todo el país contra la Nueva Ley General de Educación" (Ribas, 2007: 13). "Fuimos muchos los que pensamos que a través de la política conseguiríamos cambiar el mundo", señalaba Ribas, que encontró en la utopía sesentayochista su principal leitmotiv en los setenta. En una reciente exposición celebrada en la capital catalana con motivo del cuadragésimo aniversario de Ajoblanco, su principal promotor no dudaba en referirse a las Jornadas Libertarias de 1977 como el "Mayo del 68 catalán", destacando, como también hace en sus memorias, el ambiente antiautoritario que se respiraba en Barcelona (Europa Press, 2017).

Este tipo de reflexiones trascienden la subjetividad de sus protagonistas y dan cuenta del impacto del 68 y sus vidas posteriores durante los últimos años del franquismo. La huella que tuvo esa recepción también queda patente en la publicación de una entrevista con el conocido activista Daniel Cohn Bendit en el número de Ajoblanco de septiembre de 1977. El líder estudiantil, que llamara en mayo de 1968 a "una experiencia de ruptura completa con esta sociedad", copó muchas de las portadas de la prensa del momento, permitiendo nuevamente apreciar la atracción y el interés que suscitaba el mayo francés en sensibilidades acogidas al amplio espectro libertario, coincidiendo con los inicios del proceso transicional y la muerte del 68 proclamada por los apologistas de la reforma política (Ribas, 2007: 500).

Desde los momentos inmediatamente posteriores a lo acaecido en Francia, Mayo del 68 se había convertido en foco de elaboración de la memoria en la España del tardofranquismo, en una suerte de conocimiento experiencial que trasmite el testimonio de quien ha vivido el momento y se niega a convertirlo en un parte de un archivo empleado por el historiador profesional para hacer aseveraciones con la supuesta ventaja de que conoce los resultados de aquella historia. Su evocación está relacionada ciertamente con el creciente abismo del olvido, ese que se abre a medida que la temporalidad se acelera y se desata la añoranza del pasado en forma de actos

\footnotetext{
14 Entrevista realizada a José Ramón Castaños el 1 de noviembre de 2008 . Nació en 1950 en la zona minera de la Margen Izquierda vizcaína. En 1967 ingresó en ETA, pasando posteriormente a posicionarse con la VI Asamblea y la fusión con la Liga Comunista Revolucionaria. Se exilió a Francia a inicios de los setenta, formando parte también de los debates de la organización en América Latina. Posteriormente estuvo en Madrid de modo clandestino, hasta su vuelta a la legalidad en el País Vasco a partir de 1977. Fallecido en 2018.
} 
conmemorativos, instituidos como remedios nostálgicos frente a la irreversibilidad del tiempo. La lógica que ha guiado las lecturas del 68 en España, desde la transición a esta parte, contrasta con el poderoso utopismo que emanaba del 68 por parte de una izquierda autopercibida como nueva y heredera, en cierta medida, de luchas anteriores. Y es que como señalara en 1987 el filósofo Javier Sádaba, la palabra "utopía”, y por extensión todo lo vinculado al 68, había sido convertida en "una especie de insulto" desde los inicios de la transición (Sádaba, 1987: 88). O por marcarlo de otra manera, en ausencia de un acontecimiento, un mayo, que precipitara una salida distinta a la crisis de la dictadura, la transición se había construido y legitimado a sí misma como una alternativa a los desmanes indeseables de las utopías. Un episodio reducido por la historiografía a "algo menos que una difusa hemorragia emocional y no mucho más que un gesto de complicidad” (García Gracia y Carnicer, 2001: 338).

Este tipo de análisis histórico ha abundado en la derrota del 68 insistiendo una y otra vez en que no sucedió nada; si acaso una suerte de abstracción metafísica sin efectos reales. Pero estas opiniones que insisten en aislarse de los debates internacionales en torno al 68 no se quedan en el pasado: la producción historiográfica más actual está saturada de lo que François Cusset denomina los "contradiscursos de mayo". Antonio Elorza, por ejemplo, defiende que su herencia ha sido un relativo desdén por la democracia y la aceptación del utopismo gratuito, mientras que Ramón González Férriz se acoge a la idea de que la protesta desató el espejismo de que el orden podía ser transformado, si bien nada de aquello tuvo lugar (Elorza, 2018; González Férriz, 2018).

\section{MAYO DEL 68 O EL PASADO COMO INSPIRACIÓN DEL FUTURO}

La nostalgia generalizada, el anhelo de un pasado que en realidad, nunca existió, sugiere que todavía tenemos ideales, aunque los hayamos enterrado vivos".

Bregman, 2017, 2715

Para el pensamiento antiutópico es posible que nada ocurriera porque en sus especulaciones todo lo que acontece es siempre fuente de incertidumbre. Son sus miedos lo que operan como espectros que ocultan lo sucedido. Ahora bien, lo que ya no está presente no es puro hecho histórico; es más bien acontecimiento: sus propias lógicas se despliegan cada vez que forma parte de nuestros pensamientos personales o públicos sobre el tiempo y sus consecuencias. La nostalgia del 68 es un renglón escrito por la necesidad acuciante de novedad, de cambio y de movimiento; es una emoción propia de la modernidad, pero también un acusado sentimiento de pérdida y de derrota, derivado de aquellos proyectos de transformación que nunca llegaron a triunfar. La insistencia en acudir al 68, en ese sentido, no discurre en un sentido celebratorio, sino que transcurre fundamentalmente en términos de melancolía y duelo. La ambivalencia semántica del 68 no se puede entender sin la impronta emocional que entraña el recuerdo de quienes experimentaron el colapso de sus expectativas utópicas y se vieron relegados al vertedero de la historia, convirtiéndose en poderosas voces críticas de la modernidad y de la teleología del

\footnotetext{
15 Rutger Bregman, Utopia para realistas. A favor de la renta básica universal, la jornada laboral de 15 horas y un mundo sin fronteras, Barcelona, Salamandra, 2017, p. 27.
} 
progreso. Es por ello que el recuerdo de Mayo de 1968, como ponen de manifiesto Octavio Alberola y Ariane Gransac, pueda considerarse un hecho anacrónico pero solo si lo comparamos con "el conformismo imperante"; para estos dos pensadores, con todo, debe ser entendido como una memoria necesaria dirigida a "recuperar la esperanza en otro mundo mejor", alertando, eso sí, de los peligros subyacentes a los intentos de "celebrar el pasado mitificado o [...] revivirlo nostálgicamente” (Alberola y Gransac, 2018, 75 y 78).

La necesidad o nostalgia de "recuperar" es culturalmente comprensible dado el sentido de historicidad y singularidad del pasado construido por la modernidad desde el siglo XIX. La cuestión debe ser, por tanto, en qué términos proceder a dicha recuperación. Frente a la nostalgia que mira al pasado anhelando el viejo orden frente a lo mutable, cabe introducir otro tipo de nostalgia. Es la que Peter Glazer denomina nostalgia radical o subversiva y que va orientada a cuestionar el conservadurismo imperante en el presente estático impuesto por el nuevo orden liberal, el mismo que amenaza con destruir en sentido político de la acción de los sujetos y el derecho que les asiste a contar su propia versión de lo acontecido (Glazer, 2005, 35). La nostalgia que planteamos como conclusión de este texto permite preservar la esperanza en un mundo sin esperanza, así como elaborar lecturas radicales del pasado que desestabilicen, desnaturalicen, hagan "temblar al presente", en expresión jamesioniana. Parafraseando a Alessandro Portelli, podríamos afirmar que la nostalgia radical entraña un profundo sentido de la agencia histórica, en su insistencia en recordar que "es nuestro lado el que hace historia" (Portelli, 1990: 55). Es por ello, quizás, que una de las últimas sacudidas experimentadas por la sociedad española, el conocido como 15M, viniera precedida de llamadas a recrear "un Mayo del 68 en España"; o que en el mismo transcurrir de los acontecimientos o en las vidas posteriores de sus protagonistas hayan sido frecuentes los paralelismos entre ambos momentos históricos ${ }^{16}$.

Si bien es cierto que el tiempo concebido como irreversible e irrepetible nos hace creer en la imposibilidad de recuperar siquiera la esperanza, a menudo se cruzan en nuestra manera de pensar otras temporalidades para las cuales el pasado vuelve a aparecer en un sentido parecido al ciceroniano "historia magistrae vitae", como un compuesto reiterable de jalones episódicos. Algo parecido atraviesa las conmemoraciones: su nostalgia es parte de las contradicciones de la modernidad, derivadas del contraste entre un futuro progresivo y un pasado anhelado; ahora bien, siempre es posible que la nostalgia sea considerada no como el retorno a un pasado mitificado, en el sentido retrotópico, sino como una reflexión sobre un pasado que, aunque ya pretérito, es actualizable: hace presentes formas de pensar que ponen en cuestión la naturalidad con la que creemos que ya no hay salida posible. La conmemoración deja de ser un acto para justificar políticamente el presente como tiempo de superación frente a un pasado de violencia utópica, o como referente que opera cual espejo negativo contra el cual destacar la actualidad supuestamente dialogante y la memoria hegemónica. Ya no es tampoco el fruto de la pretensión del especialista-historiador de convertir el episodio en un suceso cerrado sobre el cual hacer enunciados "científicos" $-\mathrm{y}$, por consiguiente, monopolistas- sobre sus virtudes o vicios. Se

16 Pablo Gallego (9 de febrero de 2011). «Manifiesto Juventud: "Mayo del 68 en España" [disponible en http:// manifiestojuventud.blogspot.com/2011/02/del-68-en-espana.btml]; Nigel Townson, "El 15-M: ¿un nuevo Mayo del 68?, El País, 6-06-2011; Alberto Garzon, "Movimiento 15M y Mayo del 68", eldiario.es, 15-03-2013; Carlota Ramírez, "Cuando Mayo del 68 se encontró con el 15M", 15-05-2016. Tomás Ibáñez, "Mayo del 68, más allá del recuerdo pero muy lejos del olvido", en VVAA, Esplendor en la noche..., pp. 46-47. 
transforma, por el contrario, en un acto público en el que las memorias se enfrentan y cuyo resultado incierto puede ser la desestabilización de valores aparentemente consumados. En suma, puede que aquel pasado haya quedado desfasado, distante de nuestras formas de estar en el mundo; ahora bien, sus maneras de pensar el futuro son un revulsivo para imaginar el nuestro, lo que, desde luego, no es poco para el mundo que nos ha tocado vivir. 
Jesús Izquierdo Martín, David Beolegui Zarranz. Añorar el destiempo del 68...

\section{BIBLIOGRAFÍA}

Alverola, Octavio y Gransac, Ariane (2018). "«Mayo del 68», un hito más de la utopía”. VV.AA.. Esplendor en la noche. Vivencias de mayo del 68. Madrid: La Linterna Sorda: 75-102.

ARENDT, Hannah (2016). "Pensamientos sobre política y revolución. un comentario. (entrevista concedida a Adelbert Reif en 1970)”. La última entrevista. Barcelona: Página Indómita.

ArTiMÉ, Manuel (2018). España. en busca de un relato. Madrid: Editorial Dykinson.

AUZIAS, Claire (2018). "Un mayo menor". VV.AA, Esplendor en la noche. Vivencias de mayo del 68. Madrid: La Linterna Sorda: 114-142.

BAlestrini, Nanni, MORONI, Primo (2006). La horda de oro. La gran ola revolucionaria y creativa, politica y existencial (1968-1977). Madrid: Traficantes de Sueños.

BARbey, Bruno (2018). "Regreso a mayo del 68”. El País Semanal, 21 de abril de 2018.

Bauman, Zygmunt (2017). Retrotopía. Barcelona: Paidós.

Beorlegui, David (2007). Transición y melancolía. la experiencia del desencanto en el País Vasco. Madrid: Postmetrópolis.

BOYM, Svetlana (2015). El futuro de la nostalgia. Madrid: Antonio Machado Libros.

BREgMAN, Rutger (2017). Utopía para realistas. A favor de la renta básica universal, la jornada laboral de 15 horas y un mundo sin fronteras. Barcelona: Salamandra.

CASANELlas, Pau (2014). Morir matando. El franquismo ante la práctica armada. Madrid: Los Libros de la Catarata.

Cebeiro, Jesús (2018). “Mayo del 68”. El País, 5 de mayo de 2018.

EUROPA PRESS (2017). "La Suñol celebra 40 años de Ajoblanco”, 30 de marzo de 2017.

Glazer, Peter (2005). Radical nostalgia. Spanish Civil War Commemoration in America. Rochester: University of Rochester Press.

GILDEA, Robert, Mark, James y Warring, Anette (2013). Europe 1968's. Voices of Revolt. Oxford: Oxford University Press.

FLEITES, Álvaro (2009). “¿Retirarse a tiempo? La visión de 1968 francés en la España contemporánea”. Historia Actual Online 19 (primavera 2009): 163-176.

IBÁÑEZ, Tomás (2018). "Cronología (subjetiva) de mayo del 68”. VV.AA, Esplendor en la noche. Vivencias de mayo del 68. Madrid: La Linterna Sorda: 50-73.

IBÁÑEZ, Jordi (2009). Antígona y el duelo. Una reflexión moral sobre la memoria bistórica. Barcelona: Tusquets Editores.

ITURBE, Lola (2017). “El Mayo de 1968”. VV.AA., Esplendor en la noche. Vivencias de mayo 1968. Madrid: La Linterna Sorda: 142-161.

Koselleck, Reinhart (1993). Futuro pasado. Para una semántica de los tiempos históricos. Barcelona: Paidós. 
LE GOFF, Jacques (1998). L’héritage imposible. París: La Découverte.

LeguineChe, Manuel (1999). “Aquel año 68”. Protagonistas del siglo XX. Madrid: El País.

Elorza, Antonio (2018). Utopías del 68. De París y Praga a China y México. Madrid: Pasado y Presente.

Gracia Gracía, Jordi, Ruiz Carnicer, Miguel Ángel (2001). La España de franco (1939-1975). Madrid: Síntesis.

GONZÁLEZ, Ramón (2018). 1968: el nacimiento de un mundo nuevo. Barcelona: Debate.

MARÍAS, Julián (1977). “El ejercicio de la libertad”. El País, 14 de agosto de 1977.

MARWICK, Arthur (1998). The Sixties: Cultural Revolution in Britain, France, Italy, and the United States. Oxford: Oxford University Press.

MCLAUGHIN, Katie (2014). “Eight Unforgettable Ways 1968 Made History”, CNN, 31-07-2014.

PASSERINI, Luisa (2006). Memoria y utopia. La primacia de la intersubjetividad. Granada: Universidad de Valencia-Universidad de Granada.

PASSERINI, Luisa (2004). Autobiography of a Generation: Italy, 1968. Middletown: Wesleyan University Press [1996].

PASTOR, Jaime, GARí RAMOS, Manuel (2009). 1968: el mundo que pudo cambiar de base. Madrid: Los Libros de la Catarata.

Portelli, Alessandro (1990). "Uchronic Dreams. Working Class Memory and Possible Worlds". Raphael Samuel y Paul Thomson (eds.). The Myths We Live By. London: Routledge: 46-56.

Ross, Kristin (2008). Mayo del 68 y sus vidas posteriores. Ensayo contra la despolitización de la memoria. Madrid: Antonio Machado Libros.

SÁDABA, Javier (1987). Las causas perdidas. Madrid: Ediciones Libertarias.

Traverso, Enzo (2007). El pasado, instrucciones de uso. Historia, memoria, política. Madrid: Marcial Pons.

WALLERSTEIN, Immanuel (1989). “1968. Revolución en el sistema mundo. Tesis e interrogantes”. Estudios Sociológicos, 7, 20 (may-ago): 229-250.

WilHeLmi, Gonzalo (2016). Romper el consenso. La irquierda radical en la transición española (1975-1982). Madrid: Siglo XXI.

VV.AA. (2018). "Mayo del 68. así lo contó la prensa". El Mundo. 